\title{
QUEEN'S
UNIVERSITY
BELFAST
}

\section{The perceived impact of interprofessional information sharing on young people about their sexual healthcare}

Hyde, A., Fullerton, D., Lohan, M., McKeown, C., Dunne, L., Macdonald, G., Howlin, F., \& Healy, M. (2016). The perceived impact of interprofessional information sharing on young people about their sexual healthcare. Journal of Interprofessional Care, 30(4), 512-519. https://doi.org/10.3109/13561820.2016.1154022

Published in:

Journal of Interprofessional Care

Document Version:

Early version, also known as pre-print

Queen's University Belfast - Research Portal:

Link to publication record in Queen's University Belfast Research Portal

Publisher rights

(c) 2016, The Authors

This is an Author's Original Manuscript of an article published by Taylor \& Francis in Journal of Interprofessional Care on [date of publication], available online: http://www.tandfonline.com/[Article DOI].

\section{General rights}

Copyright for the publications made accessible via the Queen's University Belfast Research Portal is retained by the author(s) and / or other copyright owners and it is a condition of accessing these publications that users recognise and abide by the legal requirements associated with these rights.

Take down policy

The Research Portal is Queen's institutional repository that provides access to Queen's research output. Every effort has been made to ensure that content in the Research Portal does not infringe any person's rights, or applicable UK laws. If you discover content in the Research Portal that you believe breaches copyright or violates any law, please contact openaccess@qub.ac.uk. 
Hyde A, Fullerton D, Lohan M, Dunne L, Macdonald G, McKeown C, Healy M, \& Howlin F. (2016) The perceived impact of interprofessional information sharing on young people about their sexual health care. Journal of Interprofessional Care.

Accepted for publication February $10^{\text {th }} 2016$

\title{
THE PERCEIVED IMPACT OF INTERPROFESSIONAL INFORMATION SHARING ON YOUNG PEOPLE ABOUT THEIR SEXUAL HEALTH CARE
}

Abbey Hyde, Deirdre Fullerton, Maria Lohan, Laura Dunne, Geraldine Macdonald, Caroline McKeown, Maria Healy, Frances Howlin.

\begin{abstract}
This paper presents the results from an analysis of data from service-providers and young adults who were formerly in state care about how information about the sexual health of young people in state care (YPISC) is managed. In particular, the analysis focuses on the perceived impact of information sharing between professionals on young people. Twentytwo service-providers from a range of professions including social work, nursing and psychology, and 19 young people aged 18-22 years who were formerly in state care participated in the study. A qualitative approach was employed in which participants were interviewed in depth and data were analysed using modified analytical induction (Bogdan \& Biklen 2007). Findings suggest that within the care system in which service provider participants worked, it was standard practice that sensitive information about a young person's sexual health would be shared across team members, even where there appeared to be no child protection issues. However, the accounts of the young people indicated that they experienced the sharing of information in this way as an invasion of their privacy. An unintended outcome of a high level of information-sharing within teams is that the privacy of the young person in care is compromised in a way that is not likely to arise in the case of young people who are not in care. This may deter young people from availing themselves of the sexual health services.
\end{abstract}

Key words: Qualitative method; Interprofessional care; Health and social care; Confidentiality; Sexual health; Young people in state care; Looked after young people.

\section{Introduction}

Sexual health is widely considered to be the ability to have safe sexual experiences, free from coercion and without regret about the timing (Wellings et al., 2001; Mercer, 2014). There is consistent evidence internationally that young people in state care (YPISC) experience poor sexual health compared to their counterparts in the wider population (Craine at al., 2014; MacDonald, 2006). A number of studies have found YPISC to be at greater risk of early sexual initiation than those not in care (Croker \& Carlin, 2002; Jones et al., 2011) with young people in residential care particularly at risk (Carpenter, Clyman, Davidson, \& Steiner, 2001). Young people in care in both Britain and the US are frequently associated with higher rates of adolescent pregnancy and sexually transmitted infections and diseases (Dworsky \& Courtney, 2010; Twill, Green, \& Traylor, 2010; MacDonald, 2006). 
In Ireland, the location of the study reported in this article, the very limited data available suggest a similar pattern in terms of early initiation of sexual activity among YPISC (Burke et al., 2013). There is, therefore, good reason for those responsible for YPISC from a range of disciplines to pay special attention to the sexual health needs of these young people.

The aim of this paper is to present an analysis of the perspectives of a diverse group of service-providers as well as care-leavers, that is, young adults who were previously in state care $^{1}$ on how information about the sexual health of YPISC is managed with particular reference to how information-sharing between professionals impacts on the young people. We focus particularly on confidentiality (in relation to healthcare), a concept defined by Jackson and colleagues (2011) as the person's: "rights to have their personal information protected and held in trust by ... professionals", and is associated with the right to privacy (p. 656). Aptly, these authors go on to describe it as "one of the major cornerstones of health care ... ingrained into the ethos of health professional education and practice" (p. 656). They go on to note that in spite of its centrality to healthcare provision, very little critical literature has emerged relating to it, making it widely referenced but "seldom critiqued" (p. 656). We analyse the implications for the privacy of YPISC of sharing information about their sexual health within health and social care teams.

This paper is based on study findings from a wider study on the sexual education and health needs of young people in care in Ireland known as the SENYPIC (Sexual Health and Sexuality Education Needs Assessment of Young People in Care) study (Hyde et al., 2016a). Some data presented in this article are included in reports submitted to the funding body on completion of the study (Hyde et al., 2016b, 2016c).

\section{Background}

Good practice guidelines on meeting the health needs of YPISC, including sexual health needs, invoke discourses promoting interprofessional work practices (that is, individuals from diverse professions such as social work, nursing and psychology working together to deliver services), multi-agency engagement, and team work to ensure that breakdown in communication is miminized. In Ireland, these discourses are manifested in national standards for children in both residential centres (Department of Health \& Children, 2001) and foster care (Department of Health \& Children, 2003), with reference to "interdisciplinary" ${ }^{2}$ working (Department of Health \& Children, 2001, p. 19) and information sharing among professionals (Department of Health \& Children, 2003). References are also made to the maintenance of "appropriate levels" of privacy and confidentiality in relation to case and care records (Department of Health \& Children, 2001, p. 20).

The National Institute for Health and Care Excellence (NICE) (2013) in Britain, an organisation charged with offering national guidance and advice based on evidence to improve health and social care, also emphasises a collaborative team approach consisting of key professionals and frontline practitioners that may include foster or residential carers. It recommends the sharing of information among healthcare professionals, social workers and other professionals, drawing on evidence that "for the 'team around the child' to provide effective care, professionals need to collaborate closely and share relevant and sensitive information" (NICE, 2013, p. 28). The report simultaneously refers to the 
importance of YPISC having someone in whom to confide and for confidentiality to be maintained in light of research evidence that these young people report being mistrustful of talking to professionals because of doubts that the information disclosed would be kept confidential.

The importance of confidentiality has also emerged in a small number of empirical studies focusing on the sexual health of YPISC in Britain (McFeely, 2005; Billings, Hashem, \& Macvarish, 2007; Chase, Maxwell, Knight, \& Aggleton, 2006) and the USA (Constantine, Jerman, \& Constantine, 2009). Billings and colleagues (2007), based on six focus groups with twenty 15-20 year-old YPISC and care-leavers found that participants linked trust to confidentiality when discussing healthcare interactions, and revealed fear that confidentiality would be breached, generating a distrust in the system. Chase et al. (2006, p. 441), in a UK Department of Health-funded study on teenage pregnancy among young people in and leaving care (based on interviews with 63 young people currently or previously in care) similarly noted that "concerns about a lack of confidentiality or being judged meant that very few young people accessed sexual health services outside of their care setting". In the USA Constantine et al. (2009) undertook research to assess the need for, and the provision of, sex education and reproductive health services among young people in foster care and those leaving care in three California counties. They found that professionals providing services to these young people had themselves concerns about liability and confidentiality that constituted barriers in addressing the sexual health needs of the young people.

Professionals' concerns about liability in relation to supposedly confidential information is important in the Irish context because, at the time when data for the study were collected (2012-2013), legislation and policies relating to child protection were changing rapidly. This resulted in reported uncertainty and anxiety among health and social care professionals about how information pertaining to underage non-abusive sex ought to be managed (Hyde et al., 2016b). There was also an anomaly between the age of consent for intercourse (both heterosexual and homosexual) at 17 years (Criminal Law (Sexual Offences) Act 2006) and the age of independent consent for medical treatment at 16 years (Non-Fatal Offences Against the Person Act 1997), including hormonally-based contraception and sexually transmitted infection (STI) testing.

While the research reviewed above points to the importance of confidentiality to YPISC when handling information about their sexual health, very little detail is provided in this literature on how information about sexual health is handled by professionals across care teams, nor about how sexual health information management is experienced by the young people. In the analysis that follows, we endeavour to illuminate both the perspectives of professionals and the experiences of young people in this regard.

\section{Methods}

This paper presents findings from a qualitative study that used modified analytical induction (Bogdan \& Biklen 2007) and was part of a multi-phased programme of research designed to identify the sexual health needs of YPISC from the perspectives of service- 
providers, foster carers, birth parents, and young care-leavers. This article draws on data from in-depth interviews with both service-providers and care-leavers.

\section{Data collection}

In the case of each participant group (service-providers and care-leavers), interviews were loosely structured around a topic guide, with topics drawn from both existing literature and findings from a survey at an earlier phase of the SENYPIC study. The topic guide for service-providers covered participants' perceptions of the specific needs of YPISC in terms of sex education and sexual health service provision. The topic guide for the young careleaver interviews was designed to capture information on sex education; sexual behaviour and factors influencing sexual behaviour and attitudes. Given the range of topics covered in the in-depth interviews, an enormous volume of data were gathered and analysed using a qualitative strategy described further on. The focus of this article is on just one of the issues that emerged inductively from data, namely, the impact on young people in state care of information-sharing between professionals about their sexual health. That this issue emerged in the course of the interviews is significant since as Smith and Osborn (2008, p. 64) note, issues that "have come unprompted from respondents . . . are likely to be of especial importance for them".

Service providers. Recruitment of the service-providers was influenced by the outcome of an earlier phase of the SENYPIC study, namely an e-survey of service-providers whose role potentially placed them in positions of being knowledgeable about the sexual health needs of young people in care (Fullerton et al., 2016). A request was made to those responding to the e-survey to voluntarily supply their contact details should they wish to participate in a further phase of the study that involved being interviewed by a member of the research team. Twenty-two (out of a total 92 who volunteered) service provider interviews were conducted. This sample allowed the saturation of data, that is, to reach a point where new incoming data were not adding anything particularly novel to the overall analysis, but were simply confirming emerging patterns. The rationale behind purposefully selecting these 22 was the centrality of their position in understanding the sexual health of young people in care.

Prior to the in-depth interviews, potential participants were sent an information sheet detailing the study. Interviews were conducted by telephone, apart from in three cases where they were face-to-face. Interviews were audio recorded with the permission of participants. The duration of the interviews ranged from 30 minutes to 1.5 hours, with most lasting approximately one hour. Variation in interview length is a normative feature of qualitative interviewing and is a quality of its flexibility (Stier, Adler \& Clark, 2008).

Young care-leavers. Young care-leavers were deemed to be particularly useful informants for the study by virtue of their recent experiences in care, minimising the threat of recall difficulties, and harnessing the benefits of retrospective reflection when the immediate sensitivity associated with an experience may have appeased (Brener, Billy, \& Grady, 2003). An age limit of 22 years was set for participants to ensure memories of would be relatively fresh. Participants were recruited through key service-providers identified at 
earlier stages of the SENYPIC study. These service providers were involved in organisations dealing with young people in care and in providing aftercare services. The service-providers were given an information sheet about the study, supplemented with verbal information from a member of the research team. They acted as conduits of information initially and identified potential participants who were willing to meet a member of the research team. It is not known exactly how many young care-leavers were invited to participate in the study as the research team did not wish to burden service-providers with the need to maintain a record of those invited, particularly as recruiting participants to studies of this type is problematic (Dale \& Watson, 2010). In any case, in keeping with qualitative methodological strategies, the sample was purposeful, that is, designed with the purpose of including information-rich participants (Quinn Patton, 2015) rather than be representative of care-leavers in the population. Nineteen care-leavers participated from whom informed consent was obtained prior to interview.

Data were gathered from care-leavers using face-to-face individual in-depth interviews, apart from in two instances where participants were friends and were more comfortable being interviewed in pairs. This amounted to 17 interviews in total. Data collection occurred at a private space on the premises of various organisations from where participants were recruited; these organisations included aftercare/homeless organisations, an advocacy organisation centre, training centres and colleges, family support services, Health Service Executive aftercare services and parenting support services. As occurred in the case of service-provider interviews, interviews with careleavers varied in length, and were between 40 minutes and 1 hour 20 minutes.

\section{Data analysis}

Interviews of both sets of participants were transcribed in preparation for analysis. The strategy for data analysis (in relation to both sets of transcripts) resembled a strategy developed by Bogdan and Biklen (2007) referred to as modified analytical induction (MAI). It involved comparing whole interviews with each other, rather than slicing data into segments from the outset, as occurs in some types of qualitative data analysis. In this study, it involved taking the first whole transcript, paraphrasing the voice of the participant (raw data) and processing that through the researcher's repertoire of scholarly discourses (derived from social science literature) in order to make sense of it. This type of processing is a fundamental assumption in using an interpretative approach to a study and in analysing qualitative data.

From this first layer of analysis, particularly telling segments of data that most represented important points were identified. The substance of each subsequent transcript was folded into the emerging picture so that the whole account was filled out, accommodating both similar and new insights (negative cases). The analysis continued until all transcripts had been analysed and incorporated into the overall account, with pertinent quotations included in order to provide direct empirical evidence to support points where appropriate. In practice, later interviews tended to add little to the emerging account, or only altered particular components of the whole picture as the analysis became saturated. This type of strategy ensured that aspects of data that contradicted the broad pattern were accommodated, but with their scope and strength acknowledged in the text. 
In undertaking this analysis, there was an acknowledgement that individual researchers produce a unique analysis influenced by "differences in their philosophical and theoretical commitments and styles" (Sandelowski, 1993, p. 3). While the initial analysis as described was undertaken by the principal researcher, other members of the research team were encouraged to evaluate and challenge the evolving interpretations, and adjustments were made where a more convincing interpretation was offered. Like Sandoloswki (1993) we rejected the version of trustworthiness proposed in some qualitative textbooks that a single interpretation must or can be sought through member checking since this contravenes the very basis of reality as a culturally and historically situated process.

\section{Ethical issues}

Ethical approval for the study was obtained from University College Dublin (reference number: LS-11-174/LS-12-139.) Special consideration was given to the sensitivities around interviewing potentially vulnerable young adults, and provisions were made for referring any participants to support services following the interview if deemed appropriate. However, since all care-leaver participants were recruited via social services in the first instance and were already well linked to health and social service provision, it was not deemed necessary to refer any participant to an additional service.

\section{Findings}

\section{Service-provider participants}

Twenty-two service-providers participated, seventeen females and five males, all of whom had at least three years' experience in either health or social care. Participants were engaged in both direct service-provision (delivering the sex education and sexual healthcare) and indirect provision (such as training staff in the area of sexual health or in supervising those providing direct care to YPISC). The sample included those working in the following areas: social work, social care, counselling, project work, outreach services, health promotion, nursing, youth work, health work and education.

\section{Care-leaver participants}

The sample consisted of 19 care-leavers aged $18-22$ years, 16 young women and three young men. Many had experienced initial short-term care arrangements or emergency care prior to longer term placements, and several had experienced multiple moves. Ten participants had experienced residential care of at least a year's duration, with one having spent 12 years in residential care. The remaining nine experienced foster placements of at least two years' duration. Two participants experienced both foster care and residential care, each on a long-term basis. Among those previously in residential care, diverse types of residential settings were experienced, ranging from regular children's residential care homes, accommodation for homeless people, a hostel and a high-support unit, that is, a unit that provides a residential service to YPISC in need of specialised targeted interventions. Of the 19 participants, nine had become teen parents at the time of the interview. There was a good geographical spread achieved across Ireland with representation from the two main cities as well as towns in rural areas.

\section{Service-providers' perspectives}

A key finding to emerge in the accounts of service-providers was the multiplicity of professionals who were routinely privy to the intimate lives of the young people in their 
care. Several participants alluded to the complexity this created in the case of young people in residential care in particular because layers of stakeholders were often required to negotiate a sexual health service. One service manager provided the following description of the range of professionals involved in YPISC accessing contraception or emergency contraception, even where they were over 16 years of age, comparing this unfavourably with the less complicated process for those not in care:

\begin{abstract}
I think it is a little bit more difficult when they are in care because there are so many people who have a say. If a young person who is 16 wants to get the morning-after pill or wants to go on the pill or wants to get the bar [contraceptive implant] in, then they have to discuss that with their key worker who will discuss it with the manager of the unit who will discuss it with the child care manager . . .If a young person at home wants the bar in they will talk to their mother about it or they come in and get it. (Service Manager)
\end{abstract}

The participant went on to clarify that her criticism was not in any way directed at those at the front line of caring, who in her experience were not "unreasonable". Rather, she indicated that she wished to convey that, "it is always easier to talk to one person than it is to know if you talk to one person, then six people are going to be aware of the conversation". She was of the view that once individuals reach 16 years, they should have the right to make decisions about safer sex themselves and that when they reach 17 years (the legal age to consent to intercourse), their position should be no different to that of young people in general. She also shared her observation that, while the legal implications of young people in general of 15 years seeking emergency contraception were no different from those of YPISC, the former "could probably chance it", that is, had a higher probability of informally circumventing legal barriers by claiming that they were older than their years. This perspective was shared by a social worker who noted that "in an ordinary family if a teenage girl needed the morning-after-pill they could access it by parents through the GP" (Principal Social Worker). She referred to decisions by GPs to prescribe emergency contraception to underage minors without the knowledge of the social worker as a practice sometimes met with pragmatic relief:

We often find out that the doctor did give the 14 -year-old the morning-after-pill and sometimes we're nearly glad that that happens without our knowledge because it can become, well, it would have to go through the social worker and all that. (Principal Social Worker)

Another participant noted that, for reasons of confidentiality, she and a nurse on an interprofessional team were the only team members privy to a 17 -year-old resident being taken for STI screening. When other team members later learnt of the clinic visit, she described them as having been "very angry that they hadn't been told" (Psychologist). This suggests that professionals on a team expect to be apprised of details about a young person's health, problematizing the containment of sensitive information.

The implications for the young person's privacy of so many professionals having access to such sensitive and personal documented information about them, particularly in the context of staff turnover, was acknowledged as follows: 
There's also the thing about over the years so many professionals knowing so much about them, which is hard on the young person too - 'Here's another new one, new member of staff she's going to be reading my files'. There's a privacy things there too. It's very hard on the young person. . Breakdown in staff is difficult for them. I have come across people who have had 25 or 30 social workers and whatnot over their life. (After-care Worker)

A social worker reported that even a simple request for paracetamol for menstrual pain was difficult for a 13- or 14-year-old, as this may be documented in a log book and open to male staff as well as Health Information and Quality Authority (HIQA) personnel to read. While acknowledging that residential managers were required to record such events, she contrasted this with the situation for a girl in her family home who might just inform her mother that she was taking paracetamol from the medicine chest.

\section{Young people's experiences}

From the perspective of care-leaver participants, several recounted experiences of being at the receiving end of services where a range of service-providers shared information with one another, including that pertaining to sexual health. One care-leaver participant, AnnMarie, revealed her lack of trust that confidentiality would be maintained from her experience of one professional passing information on to another:

\footnotetext{
But when you are in care you have to see a counsellor at least once a week. So I agreed to see one guy and he wasn't too bad because the woman [other psychologist] was very, like, l'd tell her something and she'd go straight outside and tell. (Ann-Mariez)
}

Fiona, who had been cared for by the same foster family since she was a toddler, described the impact of having social care staff such as a social worker outside the family having oversight of her behaviour, including her sexual behaviour. She described how this layer of surveillance disrupted her sense of developing a "normal life". In the account that follows, she also proposed that official monitoring as occurs for those in care controlled what information she imparted to her foster parents, and made her cautious about sharing certain information with them:

\footnotetext{
But I think what I hated about being in care, if you done anything the social worker was on top of you. And that is not what you want - You want to grow up and you want to live a normal life and who you class as your family now. And it is like if you do anything wrong your family can't discipline you, it has to be a social worker to come in and do it. And you'd be scared of that too because if you done something and you wanted to tell your foster family that you slept with somebody or whatever, you are not going to do that because the social worker is going to come in and talk to you and you are going to get a whole eating for it. Like you are not going to go and tell them what you done. (Fiona)
}

The intermediary invigilating role of social care professionals also had implications for the young person's levels of trust with foster parents. This is exemplified in an account by Louise, who reported her belief that information she relayed to her foster parents would in turn be conveyed to the social worker: 
You can trust them [foster parents], you can and you can't. Like you can trust them to a certain extent, but you can't because you know whatever you tell them is going to be passed onto the social worker. (Louise)

Fiona also reported that the reverse was an issue - disclosing information to a social worker ran the risk of foster parents being informed of issues that the young person may wish to keep from them.

Keeping personal information to oneself was one strategy used by a participant, Catherine, to retain control over her actions. She reported that once she reached 16 years she maintained her privacy by withholding information from care staff (in a residential setting) about her physician appointments for contraception. Once staff became aware that an appointment was pending or had occurred, she indicated that they were eager to investigate the basis of the consultation. Whether or not she chose to disclose to staff the rationale for the visit depended on her own preference:

\footnotetext{
Oh yes! They were very nosey. 'Oh I am going to the doctor." "What is that prescription for?' They were very nosey - They liked to know what was going on. Interviewer: And did you tell them?

Depending, well I would have said, 'I am on a contraceptive now, I am taking something.' (Catherine)
}

It seems from her account that Catherine did retain a good deal of control over access to contraception by virtue of the strategy she employed.

\section{Discussion}

Findings from this study suggest that within the system of care in which service provider participants worked, it was standard practice that sensitive information about a young person's sexual health would be shared between different professions, even where there appeared to be no child protection issues from the perspective of the service provider. The retrospective accounts of the care-leaver participants indicate that they were well aware that information was, or could be shared and this compromised their sense of privacy and was a source of concern for YPISC. Other studies have also reported the concerns of YPISC about confidentiality in relation to their sexual health (Billings et al., 2007; Chase et al., 2006). Compared to previous studies (Billings et al., 2007; Chase et al., 2006), however, ours provides far more empirical examples and offers an analysis of the impact on the young people of information-sharing between professionals that has not featured in existing studies.

That the issue of information sharing arose as an unprompted topic in a study designed to identify sexual health needs of YPISC indicates its relevance for this category of young people, particularly since it was recognised by both service-providers and care-leaver participants as a particular issue for YPISC. What this study adds by researching both the perspectives of service providers as well as YPISC is evidence that the concerns of YPISC in care, at least in the Irish context, appear to be well-founded; sensitive information about their sexual health was shared between health and social care professions. Moreover, based on the accounts of participants, service-providers generally appeared to 
operationalise what are formally defined as good sound practices in terms of communicating information effectively with colleagues (NICE, 2013). As indicated in findings, where information about sexual health was not apparently shared (as was reported when a 17 year old attended for STI testing without the knowledge of some professionals), the reported negative reactions of those not apprised of the situation suggest that in the care setting in question, professionals who had a stake in the care of a young person expected to be informed about issues affecting him or her.

The attempt in official practices to moderate risk by tackling professional "silos" (Parton 2011) is through information sharing and interagency working. Indeed, since interprofessional communication failures have been associated with poor health outcomes (e.g. Brock at al. 2013; Kasprzyk et al. 2014; Harrington \& Whyte 2015) it is easy to understand why professionals might be inclined to err on the side of caution and share information liberally with each other. Nonetheless, our findings indicate that an unintended outcome of a high level of information-sharing is that the privacy of the young person in care is compromised to a greater extent than is likely to arise in the case of young people who are not in care, and YPISC are affected negatively by this.

Other implications from our findings may be that fear of breaches in confidentiality may result in YPISC choosing not to access the sexual health services when it may be in their best interests to do so. If we turn to studies on adolescents in general in the absence of those specifically on YPISC, these suggest that confidentiality in relation to sexual health is extremely important to teenagers (Thomas, Murray, \& Rogstad, 2006) and fears around confidentiality breaches are the principal deterrent to their seeking sexual health advice (Royal College of General Practitioners' Adolescent Health Group, 2011). Thomas et al.'s (2006) UK-based survey of 13-14 year olds found that over half rated confidentiality as most important feature of health services and the vast majority reported being more likely to use a service if it were confidential. Almost two-thirds reported that they would not attend if they believed that child protection services were to be informed of their visit. The authors concluded that ". . . if confidentiality is lost, young people may not attend, or may not be honest when they utilize a sexual health service" (p. 525). Carlisle, Shickle, Cork and McDonagh (2006, p. 136) came to a similar conclusion about confidentiality in medical consultations between doctors and young people, finding that it was of "paramount" importance to young people. They concluded that the openness of young people in medical consultations could be improved were doctors to take the time stress the confidential nature of the encounter. Indeed a systematic review of contraceptive service delivery to young people in the UK based on 59 articles concluded that the most dominant concern for young people was that anonymity and confidentiality be maintained (Baxter, Blank, Guillaume, Squires, \& Payne, 2011); these authors stressed the importance of young people being reassured about this. These studies, as indicated, related to young people in general and not those in state care, but the implications of information being shared between health professionals are greater for young people in care who interface with multiple professionals and who may well be deterred from availing of the sexual health services as required.

Based on these findings we recommend that further research is conducted specifically on the topic of how professions deal with YPISC work, particularly on how sensitive 
information is recorded and relayed between professionals. This would allow protocols to be developed that satisfy the need to ensure that information necessary to protect the young person is disclosed and communicated, yet at the same time ensuring that information is contained where appropriate. We recommend that the rights of the young person to privacy should be afforded greater attention in any guidelines for the professional team around the child as far as sharing relevant and sensitive information is concerned. We also propose that professionals receive education and guidance to enable them to discern what information to share, what to document and what to treat as a private matter between themselves and the young person. Team members may also need to appreciate that they may not be apprised of all matters relating to a young person where it is in the best interests of the young person to minimise the number of people privy to such information.

Because the impact of information sharing between professionals emerged inductively in the data, the study is limited by not having explored contextual issues around informationsharing and confidentiality such as how teams work and what confidentiality means for YPISC. In addition, since ours was a purposeful sample in a specific context, data gathered in our context may have limited transferability to other contexts; the extent to which YPISC as a broad group are affected by how information about their sexual health is managed was not captured. A quantitative survey with a larger sample size is a more appropriate methodology to achieve representativeness; however, surveys are less useful for capturing depth in experience. Other limitations of our study are that the views of participants are self-reported perceptions and their actual observed experiences were not captured.

\section{Concluding comments}

That "teams" are ill-defined means that sensitive information may be circulated across a wide professional jurisdiction, involving a range of professionals who may claim a legitimate professional interest in a young person's sexual health. The diffusion of the corporate parent role in practice thus runs the risk of a young person's intimate behaviour becoming everyone's business, at least the business of an extensive range of professionals. In turn, this diffusion of the corporate parent role may inhibit open one-to-one communication between YPISC and foster parents because of the imperative to share information beyond the familial context.

\section{Declaration of Interest}

The authors declare no conflicts of interest. The authors are responsible for the writing and content of this paper.

\section{Acknowledgement}

The authors express their thanks to the Health Service Executive Crisis Pregnancy Programme for funding this study. The opinions expressed in this publication are of the researchers and are not necessarily those of the sponsor, the Health Service Executive Crisis Pregnancy Programme.

\section{References}


Baxter S, Blank L, Guillaume L, Squires H, Payne N. (2011). Views of contraceptive service delivery to young people in the UK: a systematic review and thematic synthesis. Journal of Family Planning and Reproductive Health Care, 37(2), 71-84.

Billings, J., Hashem, F., \& Macvarish, J. (2007). Looked-after children's views of sex and relationships education and sexual health services. Kent: University of Kent.

Bogdan, R. \& Biklen, S. (2007). Qualitative Research for Education (5 ${ }^{\text {th }}$ Edition). New York: Pearson International.

Brener, N.D. , Billy, J.O.G \& Grady, W.R. (2003). Assessment of factors affecting the validity of self-reported health-risk behavior among adolescents: evidence from the scientific literature. Journal of Adolescent Health, 33, 436-457.

Brock D, Abu-Rish E, Chiu CR, Hammer D, Wilson S, Vorvick L, ... Zierler B (2013). Interprofessional education in team communication: working together to improve patient safety. BMJ Quality and Safety, 22, 414-423.

Burke, L. Gavin, A., Courtney, L., Nic Gabhainn, S. \& Kelly C. (2013). Sexual Behaviour of 1517 Year Olds in the Mid-west Region and in Care Short Report HBSC Ireland 2010. Galway: National University of Ireland, Galway.

Carlisle, J., Shickle, D., Cork, M., \& McDonagh, A. (2006). Journal of Medical Ethics, 32 (3), 133-137.

Carpenter, S. C., Clyman, R. B., Davidson, A. J. \& Steiner, J. F. (2001). The association of foster care or kinship care with adolescent sexual behavior and first pregnancy. Pediatrics 108, 1-6.

Chase, E., Maxwell, C., Knight, A. \& Aggleton, P. (2006). Pregnancy and Parenthood among young people in and leaving care: what are the influencing factors and what makes a difference in providing support? Journal of Adolescence 29 (3), 437-51.

Constantine, WL, Jerman P, \& Constantine, N.A. (2009). Sex education and reproductive health needs of foster and transitioning youth in three California counties. Oakland, CA: Center for Research on Adolescent Health and Development, Public Health Institute.

Craine N., Midgley C., Zou L., Evans H., Whitaker R., Lyone M (2014). Elevated teenage conception risk amongst looked after children; a national audit. Public Health. 128 (7), 668670.

Criminal Law (Sexual Offences) Act 2006 S. 3.1 (Ire.)

Croker AR and Carlin EM (2002). Coitarche and care: does experience of the 'looked after' system affect timing of a woman's sexual debut? International Journal of STD and AIDS, 13 (12), 812-814.

Dale, H. (2009). The sexual health needs of looked after young people. Scotland: NHS Fife. 
Dale, H., \& Watson, L. (2010). Exploring the barriers and facilitators to health research with children and young people who are looked after. Scottish Journal of Residential Childcare, 9, $37-43$.

Department of Health \& Children (2001). National standards for children's residential centres. Dublin: Department of Health and Children.

Department of Health \& Children (2003). National standards for foster care. Dublin: Department of Health and Children.

Department of Children \& Youth Affairs (2014). Cabinet approves Heads of Bill of Aftercare Bill 2014 - Minister Fitzgerald: Dublin: Department of Children and Youth Affairs. http://www.dcya.gov.ie/viewdoc.asp?DoclD=3104. Downloaded October $13^{\text {th }}$ 2014 .

Dworsky, A., \& Courtney, M. E. (2010). The risk of teenage pregnancy among transitioning foster youth: Implications for extending state care beyond age 18. Children and Youth Services Review, 32, 1351-1356.

Fullerton, D., Hyde, A., McKeown, C., Lohan, M., Dunne, L., \& Macdonald, G. (2016). Sexual Health and Sexuality Education Needs Assessment of Young People in Care in Ireland (SENYPIC): A Survey of Service-provider Perspectives. Report No 1. Dublin: HSE Crisis Pregnancy Programme and Child \& Family Agency (Tusla).

Harrington, K. and Whyte, J. (2015). The safeguarding implications of events leading to the closure of Stanbridge Earls School: a serious case review. Hampshire: Hampshire Local Safegurading Children Board.

Hyde, A., Fullerton, D., Lohan, M., McKeown, C., Dunne, L., \& Macdonald, G. (2016a). Sexual health and sexuality education needs assessment of young people in care in Ireland (SENYPIC): Composite report of findings. Report No 6. Dublin: HSE Crisis Pregnancy Programme and Child \& Family Agency (Tusla).

Hyde, A., Fullerton, D., McKeown, C., Dunne, L., Lohan, M. \& Macdonald, G. (2016b). Sexual health and sexuality education needs assessment of young people in care in Ireland (SENYPIC): The perspectives of key service-providers: a qualitative analysis. Report No 3. Dublin: HSE Crisis Pregnancy Programme and Child \& Family Agency (Tusla).

Hyde, A., Fullerton, D., Dunne, L., Lohan, M. \& Macdonald, G. (2016c). Sexual health and sexuality education needs assessment of young people in care in Ireland (SENYPIC): The perspectives of care leavers: a qualitative analysis. Report No 5. Dublin: HSE Crisis Pregnancy Programme and Child \& Family Agency (Tusla).

Jackson, D., Peters, K., Hutchinson, M., Edenborough, M., Luck, I.. \& Wilkes, I. (2011). Exploring confidentiality in the context of nurse whistle blowing: issues for nurse managers. Journal of Nursing Management 19, 655-663. 
Jones, R., Everson-Hock, E.S, Papaioannou, D., Guillaume, L., Goyder, E., Chilcott, J., ... Swann, C. (2011). Factors associated with outcomes for looked-after children and young people: a correlates review of the literature. Child: Care, Health and Development, 37, 5, $613-622$.

Kasprzyk, M., Hyland, H., Dubash, B., Creed, S. \& Taylor, D (2014) Serious case review CNo8. Devon Safeguarding Children Board.

MacDonald, W. (2006). The health needs of young offenders. UK: The National Primary Care Research and Development Centre, University of Manchester.

McFeely, S. (2005). Teenage pregnancy in looked after young people. Practice Nurse, $29,37-42$.

Mercer, C. (2014). Sexual behaviour. Medicine, 42(6), 291-293.

NICE (2013) Looked-after young people. NICE UK. National Institute for Health and Care Excellence.

Non-Fatal Offences Against the Person Act 1997 S. 23 (Ire.)

Parton, N. (2011). Child protection and safeguarding in England: changing and competing conceptions of risk and their implications for social work. British Journal of Social Work, 41 (5), 854-875.

Quinn Patton, M. (2015). Qualitative research and evaluation methods. integrating theory and practice (Fourth Edition). London: Sage.

Royal College General Practitioners (2011). Confidentiality and young people toolkit: improving teenagers' uptake of sexual and other health advice. England (city unspecified) General Practitioners' Adolescent Health Group.

Sandelowski, M. (1993). Rigor or rigor mortis: the problem of rigor in qualitative research revisited. Advances in Nursing Science, 16(2), 1-8.

Smith, J.A., \& Osborn, A. (2008). Interpretative phenomenological analysis. In Jonathan A. Smith (Ed.) Qualitative psychology: a practical guide to research methods. (Second Edition) (pp. 53-81). London: Sage.

Stier Adler, E., \& Clark, R. (2008). How it's done: an invitation to social research. (Third Edition) Belmont: Thomson Wadsworth.

Thomas, N., Murray, E., \& Rogstad, K,E. (2006). Confidentiality is essential if young people are to access sexual health services. International Journal of STD and AIDS, 17(8),525-9.

Twill, S.E., Green, D.M., \& Traylor, A. (2010). A descriptive study on sexually exploited children in residential treatment. Child Youth Care Forum, 39:187-199. 
Wellings, K., Nanchahal, K., Macdowall, W., McManus, S., Erens, B., Mercer, C.H., ... Field, J. (2001). Sexual behaviour in Britain: early heterosexual experience. Lancet, 358(9296), 1843-1850.

\section{Endnotes}

${ }^{1}$ In Ireland, a person is categorised as a child until he/or she reaches the age of 18 years, so young people in receipt of state care in their teen years remain so until the age of 18 . In addition, young adults who were formerly in care as children may receive aftercare services, that is, support up to the age of 21 years. Currently, there is a proposal to extend this to 23 years (Department of Children \& Youth Affairs, 2014).

2 "Interdisciplinary" was not defined in this document and was used in the context of professionals co-ordinating their work practices.

${ }^{3}$ Pseudonyms are used throughout. 